\title{
Chronic myeloid leukemia incidence, survival and accessibility of tyrosine kinase inhibitors: a report from population-based Lithuanian haematological disease registry 2000-2013
}

Tumas Beinortas ${ }^{1,2^{*}}$ (D) IIma Tavoriene $\dot{e}^{3}$, Tadas Žvirblis ${ }^{3}$, Rolandas Gerbutavičius ${ }^{4}$, Mindaugas Jurgutis ${ }^{5}$ and Laimonas Griškevičius ${ }^{3,6}$

\begin{abstract}
Background: Currently available chronic myeloid leukaemia (CML) survival reports have originated from more affluent countries. Herein we report the entire country data on incidence and survival of CML, as well as penetrance of tyrosine kinase inhibitors (TKls) in Lithuania.

Methods: We analyzed all patients $(N=601)$ from the national haematological disease monitoring system who were diagnosed with CML between 2000 and 2013. Crude (CR) and age-standardized (weighted) (ASW(R)) incidence and mortality rates, as well as 1-, 5-, and 10-year relative survival rates (RSR) were calculated. Information on TKI penetration is also reported.

Results: Throughout the entire 2000-2013 period the median age at diagnosis of CML patients was 62 years. The respective incidence and mortality CRs were 1.28 and 0.78 , both characterized by decreasing trends over the observation period. A 5-year RSR increased from 0.33 [95 \% Cl, 0.27-0.40] in 2000-2004 to 0.55 [95 \% Cl, 0.47-0.63] in 2005-2009. However, the respective 5-year RSRs for patients aged 65-74 and $\geq 75$ were only 0.33 [95\% Cl, 0.24-0.42] and 0.18 [95\% Cl 0.07-0.23] during the entire study period. TKI penetrance for CML patients grew from $1.5 \%$ in 2000-2004 to $30.6 \%$ in 2005-2009 and 69.1\% in 2010-2013. TKI penetrance was low in the older age groups (60\% for the 65-74 and $19 \%$ for the $\geq 75$ patient group, in 2010-2013).
\end{abstract}

Conclusion: Relative CML survival in Lithuania steadily improved and paralleled the increase in TKI treatment availability. Patients above 64 years rarely received TKIs and their relative survival remained low throughout the observation period. The latency of TKI availability may have influenced the survival trends.

Keywords: Chronic myeloid leukemia, Tyrosine kinase inhibitors, Survival, Lithuania, Drug penetrance, Drug availability, Europe

\footnotetext{
*Correspondence: tumasbeinortas@gmail.com

${ }^{1}$ Clinical Medical School, University of Oxford, Oxford, UK

${ }^{2}$ Centre for Evidence-Based Medicine, Clinics of Internal, Family Medicine and

Oncology, Faculty of Medicine, Vilnius University, M. K. Ciurlionio str. 21,

03101 Vilnius, Lithuania

Full list of author information is available at the end of the article
} 


\section{Background}

The approval of Imatinib mesylate in 2001 [1] and thereafter emergence of second generation Bcr-Abl1 inhibitors have transformed Chronic Myeloid Leukaemia (CML) from deadly to readily treatable cancer [2, 3]. IFN $\alpha$ and chemotherapy were rapidly replaced by imatinib as a mainstay treatment of CML, after clinical trial data demonstrated the treatment effect that few cancer treatments have shown before [4-6].

Although in some patients tyrosine kinase inhibitors (TKIs) may cure CML, the discontinuation of imatinib treatment in prolonged molecular remission usually leads to the molecular relapse of the disease [7]. Therefore to acquire a survival benefit, most of CML patients need to stay on TKIs for the rest of their life. With ever expanding CML patient population the financial sustainability of expensive Bcr-Abl1 inhibitors has been debated even in economically well-established countries [8]. Current cost-effectiveness and cost-utility analyses are based on data from clinical trials, which delineate strict patient inclusion criteria and provide rigorously controlled treatment regimens at university hospitals $[9,10]$. But in real life patients and treatment quality in different centers may be more variable, thus clinical trials may not always accurately reflect the treatment efficacy at a country-wide population level [11]. Population studies readily address these challenges and can accurately describe the incidence, prevalence and real-life survival of target disorder.

Currently available population CML survival data has largely originated from economically well-established countries [2, 3, 12-15]. However, some of CML survival population studies rely exclusively on regional registries linked to haematological specialty centers, rather than national cancer registries, and therefore are susceptible to referral and selection bias $[3,14]$. Complete population reports minimize the risk of selection bias, but entire country population CML incidence and survival reports are currently accessible for Sweden and United Kingdom only $[2,12,13]$.

The transitional nature of Lithuania's economy has limited the availability of cancer medicines under patent: imatinib became partially available in 2005 and fully available only in 2011. In this study we report an unselected entire country population data on CML incidence, survival and TKI penetrance in Lithuania from 2000 to 2013. We also aim to compare the CML survival differences between countries due to differences in the availability of the innovative treatment.

\section{Methods}

\section{Lithuanian HESS registry}

Lithuania has a national haematological disease monitoring system (HESS), which collects data from 2000 and covers the entire country, with a population of 3 million. Patients with haematological malignancies are managed in 5 centres across the country and all physicians and pathologists are obliged to report all newly diagnosed CML cases to HESS registry. HESS contains data on age, sex, ICD-10 code, date of diagnosis, clinical symptoms, laboratory test, risk group, treatment, $\mathrm{Ph}$ and $\mathrm{BCR}-\mathrm{ABL}$ status (both mandatory from 2010) of CML. Eastern Cooperative Oncology Group (ECOG) performance score and CML phase at presentation were collected from 2010. Through unique personal ID, HESS is also linked to the national death registry, which allows further validation of data. All Lithuanians are covered by national healthcare insurance and haematological diseases are treated in public healthcare system. Therefore underreporting to HESS registry is unlikely. All patients, who were diagnosed with CML (ICD-10 code 92.1) between January 1st 2000 and December 31st 2013, were entered into the study. There was no age restriction or other exclusion criteria. The study was conducted according to the declaration of Helsinki and was approved by the Lithuanian Bioethics Committee, which also waived the need for informed consent.

\section{Statistical methods}

Descriptive statistics were used to analyze patients' demography. Student-t or Mann-Whitney-Wilcoxon tests were used to evaluate the differences between the two independent groups. The differences between independent categorical data groups were evaluated by Fisher exact test.

Age was categorized in 10 subgroups (Additional file 1: Table S1) for incidence analysis and 5 subgroups $(<45,45-$ $54,55-64,65-74$ and $\geq 75$ ) for survival analysis. Crude and age standardized rates according to world population (CR and ASR (W), respectively) were calculated for incidence, prevalence and mortality. CR was represented as the number of patients per 100000 inhabitants per year in Lithuania [16]. ASR (W) was defined as a weighted mean of the age-specific rates [17]; the weights were taken from the standard world population [18]. Incidence rate was defined as the number of new CML cases that occurred during a given time period [16]. Mortality rate was defined as a number of deaths from any cause during a given time period [16].

Relative survival rate (RSR) was defined as observed survival in CML group divided by the expected survival of a comparable group from general population [19]. Observed and expected survival were calculated using Kaplan-Meier [20] and Ederer II [21] method, respectively. One-, five- and ten-year RSRs with $95 \%$ confidence intervals (95\% CI) were estimated. Survival time was calculated as the time from the date of diagnosis to 
death; 31st of December 2014 was set as censoring date for alive patients.

All statistics were performed by Statistical Analysis System (SAS) package version 9.2. A two-tailed $p$-value less than 0.05 was considered significant.

\section{Results}

\section{Study population}

From January 1st 2000 to December 31st 2013, 601 patients newly diagnosed with CML were included in the HESS registry. None of them were lost to follow-up. The median follow-up time for alive patients was 74 months (range 13-172). The genetic or cytogenetic confirmation of $\mathrm{Ph}+$ and/or BCR-ABL1 fusion status was available for $33 \%$ of CML diagnoses made in 2000-2004, $83 \%$ in 2005-2009 and $82 \%$ in 2010-2013 period. Throughout the 14 year period male to female sex ratio was 1.09 with median age at diagnosis of 62 (range 14-93) and 63 (range 5-94) $(p=0.170)$, respectively. Older people were more likely to suffer from CML: $47 \%$ of all CML cases were older than 65 years, although only $16 \%$ of the Lithuanian population was older than 65 years (Table 1). The median age at diagnosis was 65 years at 2000-2004, 63 at $2005-2009$ and 58 at 2010-2013 ( $p=0.288)$. During the 2010-2013 period the share of CML diagnoses in people under 65 was higher (64\%) compared to two previous periods ( $49 \%$ in $2000-2004,53 \%$ in $2005-$ 2009) $(p=0.031)$.

Table 1 CML demographics in Lithuania in 2000-2013

\begin{tabular}{|c|c|c|c|c|c|c|c|c|}
\hline \multirow[t]{3}{*}{ Demographics } & \multicolumn{6}{|c|}{ Calendar period } & \multirow{2}{*}{\multicolumn{2}{|c|}{ Total }} \\
\hline & \multicolumn{2}{|c|}{ 2000-2004 } & \multicolumn{2}{|c|}{ 2005-2009 } & \multicolumn{2}{|c|}{ 2010-2013 } & & \\
\hline & $\mathrm{N}$ & $\%$ & $\mathrm{~N}$ & $\%$ & $\mathrm{~N}$ & $\%$ & $\mathrm{~N}$ & $\%$ \\
\hline Total & 263 & 44 & 212 & 35 & 126 & 21 & 601 & 100 \\
\hline \multicolumn{9}{|l|}{ Age, years } \\
\hline Median & 65 & & 63 & & 58 & & 62 & \\
\hline Range & $5-94$ & & 9-90 & & $17-94$ & & $5-94$ & \\
\hline $0-44$ & 60 & 23 & 44 & 21 & 35 & 28 & 139 & 23 \\
\hline $45-54$ & 28 & 11 & 36 & 17 & 19 & 15 & 83 & 14 \\
\hline $55-64$ & 41 & 16 & 31 & 15 & 26 & 21 & 98 & 16 \\
\hline $65-74$ & 78 & 30 & 49 & 23 & 23 & 18 & 150 & 25 \\
\hline $75+$ & 56 & 21 & 52 & 25 & 23 & 18 & 131 & 22 \\
\hline \multicolumn{9}{|l|}{ Gender } \\
\hline Male & 139 & 53 & 108 & 51 & 66 & 52 & 313 & 52 \\
\hline Female & 124 & 47 & 104 & 49 & 60 & 48 & 288 & 48 \\
\hline
\end{tabular}

Hematopoietic stem cell transplantation

$\begin{array}{lllllllll}\text { Allogeneic } & 6 & 2 & 14^{\mathrm{a}} & 7 & 7^{\mathrm{b}} & 6 & 27 & 4\end{array}$

${ }^{\mathrm{a}} 2$ patients with double haematopoietic stem cell transplant (HSCT)

${ }^{\mathrm{b}} 1$ patient with double HSCT

\section{Incidence}

The CR and ASR (W) of CML in Lithuanian population during the period of 2000-2013 was, accordingly, 1.28 (1.44 in males, 1.15 in females) and 0.88 (1.04 in males, 0.76 in females) (Table 2). Over the 14 year period of monitoring both metrics of CML incidence in Lithuania have steadily decreased. CR fell from 1.51 in 2000-2004 to 1.03 in 2010-2013. CML incidence increased with age. It was the lowest in the $0-14$ age group $(C R=0.04)$ and the highest in $\geq 75$ age group $(\mathrm{CR}=4.36)$ (Additional file 1: Table S1). Although overall CML incidence was higher in men, greater male preponderance became evident only above the age of 60 .

\section{Accelerated phase, blast crisis and performance status}

During the 2010-2013 period, accelerated phase (AP) and blast crisis $(\mathrm{BC})$ data was available for $102(81 \%)$ and ECOG performance status for 92 (73\%) of newly diagnosed patients. At presentation $86 \%$ were in $\mathrm{CP}, 12 \%$ in $\mathrm{AP}$ and $2 \%$ in $\mathrm{BC}$. The median follow-up time for 2010-2013 cohort was 37 months (range 13-60 months). 1 patient progressed from $\mathrm{CP}$ to $\mathrm{AP}$ and 2 patients from $\mathrm{AP}$ to $\mathrm{BC}$. None of the patients presenting with AP progressed into BC. At presentation, $92 \%$ of patients below 75 years had ECOG performance status score of $0-1$ (Additional file 1: Table S9). Only $22 \%$ of $\geq 75$ age group had ECOG $0-1$.

\section{Mortality}

Throughout the entire 2000-2013 period the average mortality CR and ASR (W) were 0.78 (range 0.261.08 ) and 0.46 (range $0.13-0.72$ ), respectively. The average mortality CR and ASR (W) decreased from 0.82 to 0.69 and from 0.47 to 0.38 , respectively, comparing 2000-2004 and 2010-2013 periods. Although there was no significant difference in crude male and female mortality rates $(p=0.095)$, men had a higher overall ASR (W) mortality $(p=0.014)$ (Table 2). Older age was a strong factor for higher mortality CR throughout all time periods ( $p<0.001$ for all periods) (Additional file 1: Table S4).

\section{Survival trends}

The RSR improved with every calendar period of treatment. Overall, 1-, 5- and 10-year RSRs were 0.72, 0.49 and 0.36 , respectively. RSR trends between males and females were similar throughout the entire follow-up period ( $p=0.697$ ) (Table 3). Age was an important predictor of RSR, with younger patients having significantly better RSR than elderly. 1-year RSR has markedly increased from 0.61 [95 \% CI, 0.55-0.67] in 2000-2004 to 0.81 [95 \% CI, 0.74-0.86] in 2005-2009, but plateaued at 0.81 [95 \% CI, 0.74-0.86] during the 2010-2013 period (Table 3). 
Table 2 CML epidemiology in Lithuania in 2000-2013

\begin{tabular}{|c|c|c|c|c|c|c|c|c|c|c|c|c|}
\hline \multirow[t]{3}{*}{ Epidemiology } & \multicolumn{12}{|c|}{ Calendar period } \\
\hline & \multicolumn{3}{|c|}{$2000-2004$} & \multicolumn{3}{|c|}{$2005-2009$} & \multicolumn{3}{|c|}{ 2010-2013 } & \multicolumn{3}{|c|}{ 2000-2013 } \\
\hline & Male & Female & All & Male & Female & All & Male & Female & All & Male & Female & All \\
\hline \multicolumn{13}{|l|}{ Incidence rate } \\
\hline$C R$ & 1.72 & 1.34 & 1.51 & 1.37 & 1.15 & 1.25 & 1.17 & 0.91 & 1.03 & 1.44 & 1.15 & 1.28 \\
\hline ASR (W) & 1.20 & 0.87 & 1.00 & 1.00 & 0.72 & 0.86 & 0.88 & 0.65 & 0.75 & 1.04 & 0.76 & 0.88 \\
\hline \multicolumn{13}{|l|}{ Mortality rate } \\
\hline$C R$ & 0.98 & 0.68 & 0.82 & 0.83 & 0.80 & 0.82 & 0.82 & 0.58 & 0.69 & 0.89 & 0.69 & 0.78 \\
\hline ASR (W) & 0.62 & 0.38 & 0.47 & 0.61 & 0.46 & 0.52 & 0.52 & 0.29 & 0.38 & 0.59 & 0.38 & 0.46 \\
\hline
\end{tabular}

ASR (W) age-standardized (weighted) rate, $C R$ crude rate

A 5-year CML RSR increased from 0.33 [95 \% CI, $0.27-0.40$ ] in 2000-2004 to 0.55 [95 \% CI, 0.47-0.63] in 2005-2009 period in Lithuania. All patient groups, but those above 75, have demonstrated an increase in 5-year RSR. A 10-year RSR for the overall cohort was 0.36 [95 \% CI, 0.31-0.42]. Figure 1 demonstrates how cumulative RSR changed with every calendar period. Interestingly, during the 2010-2013 period RSR started to increase beyond 2 years after the diagnosis.

Relative survival rate was calculated by diving the observed survival ratio by the expected survival ration of age-specific general population

\section{Treatment}

Figure 2 describes the TKI availability for CML patients in different calendar periods. TKI penetrance for CML patients grew from $1.5 \%$ in $2000-2004$ to $30.6 \%$ in 2005-2009 and $69.1 \%$ in 2010-2013. Imatinib was the only first line TKI for all study periods, which was guided by the national reimbursement policy. The increased availability of TKI treatment was largely limited to younger patient groups. In 2005-2009 $49.5 \%$ and in 2010-2013 $81.0 \%$ of patients younger than 65 were treated with TKIs. Until 2009 not a single patient $\geq 75$ was treated with TKIs and even in the most recent period (2010-2013) the penetrance of TKIs in $\geq 75$ patient group remained low (18.6\%). Across all three periods, $4 \%$ of patients were treated with hematopoietic stem cell transplantation (4\%) (Table 1$)$.

\section{Discussion}

Imatinib generics are scheduled to enter US and European markets in early 2016 and the need for high quality population-level data to support better policy making is particularly increased $[9,22]$. However, population-level reports reflecting the efficacy of CML treatment in TKI era are still scarce. Several available studies stem from haematology center-based registries or regional registries. Although valuable, they ignore the impact of out-of-region referral to treatment center and practice at local hospitals on presented data [14]. Entire country registry-based studies avoid these shortcomings, but cannot provide more detailed outcomes and have no control over the treatment and monitoring of the disease. Here we present one of few national registry CML epidemiology reports covering the population of the entire country. In addition, this is the first study demonstrating the CML treatment outcome inequalities between countries, owing to differences in the availability of the innovative treatment.

The age distribution of CML cases in Lithuania was virtually identical to the European averages, as summarized in the EUTOS population-based registry and HAEMACARE project reports [22, 23]. CML incidence CR in Lithuania was not stable throughout the observation period and decreased steadily from 1.51 in 2000-2004 period to 1.03 in 2010-2013. Cumulative CML incidence seen during the entire 2000-2013 period (CR 1.28) was slightly higher than CR of 1.10 seen in 48 European cancer registries in 2000-2002 and CR of 0.99 reported from EUTOS registry in 2008-2012 [24]. Meanwhile, reports from Swedish and UK registries both demonstrated even lower cumulative annual CML incidence (CR of 0.9) [12, 25]. Interestingly, considerably higher incidence metrics are seen in USA, where annual cumulative CML incidence CR has been consistently reported at $1.7-1.8$ per 100000 population [26, 27].

Pathological and clinical diagnosis alone is known to sometimes misdiagnose $\mathrm{Ph}$ negative myeloproliferative neoplasias as CML [22]. BCR-ABL negative CML incidence was not available from the Lithuanian registry, but was previously reported to constitute $0.6 \%$ of all CML cases in USA, $2 \%$ in Italy and $4 \%$ in France $[3,28,29]$. In Lithuanian HESS registry only a proportion of CML diagnoses were genetically confirmed, especially during the earliest study period. It is the drawback of our study, which probably explains the decreasing CML incidence over years, as share of genetically confirmed CML diagnoses increased. Therefore CR of 1.03 from the most recent 2010-2013 period is likely to represent the most accurate value of annual CML incidence in Lithuania. Likewise, a low percentage of genetically confirmed CML cases are 
Table 3 One-, five- and ten-year RSR \% of CML in Lithuania

\begin{tabular}{|c|c|c|c|c|c|c|c|c|}
\hline \multirow[t]{3}{*}{ Population } & \multicolumn{8}{|c|}{ Calendar Period } \\
\hline & \multicolumn{2}{|c|}{$2000-2004$} & \multicolumn{2}{|c|}{$2005-2009$} & \multicolumn{2}{|c|}{ 2010-2013 } & \multicolumn{2}{|c|}{ 2000-2013 } \\
\hline & RSR & $95 \% \mathrm{Cl}$ & RSR & $95 \% \mathrm{Cl}$ & RSR & $95 \% \mathrm{Cl}$ & RSR & $95 \% \mathrm{Cl}$ \\
\hline \multicolumn{9}{|l|}{1 year RSR } \\
\hline \multicolumn{9}{|l|}{ All } \\
\hline $0-44$ years & 0.94 & $0.83-0.98$ & 0.91 & $0.78-0.97$ & 0.97 & $0.82-1.00$ & 0.94 & $0.88-0.97$ \\
\hline 45-64 years & 0.72 & $0.60-0.81$ & 0.89 & $0.79-0.95$ & 0.94 & $0.82-0.99$ & 0.84 & $0.78-0.89$ \\
\hline $65-74$ years & 0.43 & $0.31-0.54$ & 0.83 & $0.68-0.92$ & 0.67 & $0.44-0.84$ & 0.59 & $0.51-0.67$ \\
\hline $75+$ years & 0.35 & $0.22-0.49$ & 0.57 & $0.41-0.71$ & 0.49 & $0.26-0.69$ & 0.46 & $0.37-0.55$ \\
\hline Overall & 0.61 & $0.55-0.67$ & 0.81 & $0.74-0.86$ & 0.81 & $0.74-0.86$ & 0.72 & $0.69-0.76$ \\
\hline \multicolumn{9}{|l|}{ Male } \\
\hline $0-44$ years & 0.91 & $0.73-0.91$ & 0.85 & $0.64-0.94$ & 0.96 & $0.72-1.00$ & 0.90 & $0.81-0.95$ \\
\hline 45-64 years & 0.70 & $0.52-0.82$ & 0.90 & $0.72-0.97$ & 1.00 & - & 0.84 & $0.74-0.90$ \\
\hline $65-74$ years & 0.39 & $0.24-0.53$ & 0.81 & $0.59-0.93$ & 0.81 & $0.46-0.96$ & 0.58 & $0.46-0.68$ \\
\hline $75+$ years & 0.28 & $0.11-0.48$ & 0.54 & $0.30-0.75$ & 0.43 & $0.16-0.70$ & 0.41 & $0.28-0.54$ \\
\hline Overall & 0.58 & $0.49-0.66$ & 0.79 & $0.70-0.87$ & 0.85 & $0.73-0.93$ & 0.71 & $0.65-0.76$ \\
\hline \multicolumn{9}{|l|}{ Female } \\
\hline $0-44$ years & 0.97 & $0.78-1.00$ & 1.00 & - & 1.00 & - & 0.98 & $0.89-1.00$ \\
\hline 45-64 years & 0.75 & $0.55-0.87$ & 0.89 & $0.72-0.96$ & 0.89 & $0.70-0.97$ & 0.84 & $0.75-0.90$ \\
\hline $65-74$ years & 0.48 & $0.30-0.64$ & 0.84 & $0.61-0.95$ & 0.51 & $0.19-0.77$ & 0.61 & $0.48-0.72$ \\
\hline $75+$ years & 0.41 & $0.23-0.59$ & 0.59 & $0.38-0.76$ & 0.56 & $0.20-0.84$ & 0.51 & $0.38-0.62$ \\
\hline Overall & 0.65 & $0.55-0.73$ & 0.82 & $0.73-0.89$ & 0.80 & $0.67-0.89$ & 0.74 & $0.68-0.79$ \\
\hline \multicolumn{9}{|l|}{5 year RSR } \\
\hline \multicolumn{9}{|l|}{ All } \\
\hline $0-44$ years & 0.60 & $0.46-0.71$ & 0.90 & $0.76-0.97$ & - & - & 0.77 & $0.69-0.84$ \\
\hline 45-64 years & 0.42 & $0.30-0.54$ & 0.70 & $0.57-0.81$ & - & - & 0.64 & $0.55-0.71$ \\
\hline $65-74$ years & 0.16 & $0.08-0.26$ & 0.52 & $0.35-0.68$ & - & - & 0.33 & $0.24-0.42$ \\
\hline $75+$ years & 0.14 & $0.05-0.29$ & 0.09 & $0.02-0.22$ & - & - & 0.14 & $0.07-0.23$ \\
\hline Overall & 0.33 & $0.27-0.40$ & 0.55 & $0.47-0.63$ & $N / R$ & $N / R$ & 0.49 & $0.45-0.54$ \\
\hline \multicolumn{9}{|l|}{ Male } \\
\hline $0-44$ years & 0.53 & $0.34-0.70$ & 0.83 & $0.61-0.94$ & - & - & 0.74 & $0.62-0.83$ \\
\hline $45-64$ years & 0.44 & $0.27-0.61$ & 0.74 & $0.53-0.89$ & - & - & 0.66 & $0.53-0.77$ \\
\hline $65-74$ years & 0.14 & $0.05-0.28$ & 0.50 & $0.27-0.73$ & - & - & 0.33 & $0.21-0.46$ \\
\hline $75+$ years & 0.14 & $0.02-0.39$ & 0.16 & $0.03-0.45$ & - & - & 0.18 & $0.07-0.35$ \\
\hline Overall & 0.32 & $0.24-0.41$ & 0.59 & $0.47-0.70$ & $N / R$ & $N / R$ & 0.51 & $0.44-0.58$ \\
\hline \multicolumn{9}{|l|}{ Female } \\
\hline $0-44$ years & 0.66 & $0.46-0.80$ & 1.00 & - & - & - & 0.82 & $0.69-0.90$ \\
\hline $45-64$ years & 0.40 & $0.23-0.58$ & 0.67 & $0.48-0.81$ & - & - & 0.61 & $0.49-0.72$ \\
\hline $65-74$ years & 0.18 & $0.07-0.34$ & 0.53 & $0.30-0.74$ & - & - & 0.33 & $0.21-0.46$ \\
\hline $75+$ years & 0.14 & $0.04-0.34$ & 0.05 & $0.00-0.21$ & - & - & 0.11 & $0.04-0.23$ \\
\hline Overall & 0.35 & $0.26-0.44$ & 0.52 & $0.41-0.63$ & $N / R$ & $N / R$ & 0.48 & $0.41-0.55$ \\
\hline \multicolumn{9}{|l|}{10 year RSR } \\
\hline \multicolumn{9}{|l|}{ All } \\
\hline $0-44$ years & 0.42 & $0.29-0.55$ & - & - & - & - & 0.60 & $0.48-0.70$ \\
\hline 45-64 years & 0.29 & $0.18-0.42$ & - & - & - & - & 0.52 & $0.40-0.63$ \\
\hline
\end{tabular}


Table 3 One-, five- and ten-year RSR \% of CML in Lithuania (Continued)

\begin{tabular}{|c|c|c|c|c|c|c|c|c|}
\hline $65-74$ years & 0.08 & $0.03-0.18$ & - & - & - & - & 0.19 & $0.09-0.32$ \\
\hline $75+$ years & - & - & - & - & - & - & - & - \\
\hline Overall & 0.21 & $0.16-0.27$ & $N / R$ & $N / R$ & $N / R$ & $N / R$ & 0.36 & $0.31-0.42$ \\
\hline \multicolumn{9}{|l|}{ Male } \\
\hline $0-44$ years & 0.38 & $0.21-0.56$ & - & - & - & - & 0.58 & $0.41-0.72$ \\
\hline 45-64 years & 0.33 & $0.17-0.52$ & - & - & - & - & 0.53 & $0.37-0.69$ \\
\hline $65-74$ years & 0.04 & $0.00-0.18$ & - & - & - & - & 0.11 & $0.01-0.36$ \\
\hline $75+$ years & - & - & - & - & - & - & - & - \\
\hline Overall & 0.21 & $0.14-0.30$ & $N / R$ & $N / R$ & $N / R$ & $N / R$ & 0.37 & $0.28-0.46$ \\
\hline \multicolumn{9}{|l|}{ Female } \\
\hline $0-44$ years & 0.46 & $0.27-0.63$ & - & - & - & - & 0.63 & $0.45-0.76$ \\
\hline $45-64$ years & 0.25 & $0.11-0.42$ & - & - & - & - & 0.49 & $0.32-0.65$ \\
\hline $65-74$ years & 0.13 & $0.03-0.30$ & - & - & - & - & 0.24 & $0.12-0.39$ \\
\hline $75+$ years & - & - & - & - & - & - & - & - \\
\hline Overall & 0.21 & $0.14-0.30$ & $N / R$ & $N / R$ & $N / R$ & $N / R$ & 0.36 & $0.28-0.44$ \\
\hline
\end{tabular}

seen in the SEER data and might underlie the observed CML incidence discrepancies between USA and Europe $[22,27]$. In the latter only genetically confirmed CML diagnoses are included in the EUTOS registry. As much as $12 \%$ of new CML diagnoses in Lithuania presented in the accelerated phase, whereas they comprised only $4 \%$ of all new CML cases in Sweden and $5 \%$ in Czech Republic and Slovakia [12, 14]. However, phase at presentation data was available only for the 2010-2013 period and larger numbers will be needed to draw a definitive conclusion of higher incidence of AP-CML in Lithuania compared to other countries.

Introduction of imatinib mesylate as a first line therapy has led to great improvements in prognosis for CML patients. Treatment results in IRIS trial demonstrated a $89 \%$ overall 5-year survival for patients aged 18-70 and treated with imatinib as a first-line agent [30]. Similarly high long-term survival rates were also demonstrated in centers of excellence for CML care [31, 32]. Since oral administration of imatinib significantly reduced the complexity of care for CML patients, the treatment may be decentralized and provided outside teaching hospitals. However, a study by Lauseker et al. found that in Germany outcomes for patients treated outside teaching hospitals are markedly inferior to those treated in academic centers [33]. In Sweden academic center catchment areas also had a tendency to give superior CML treatment results to other regions, though not at a statistically significant level [12]. Thus national survival averages are likely to be worse than survival reports from sole specialty centers, or regional registries, based around tertiary haematology center.

In Lithuania, country with 3 million inhabitants, CML is treated in 5 hospitals, 2 of which are teaching

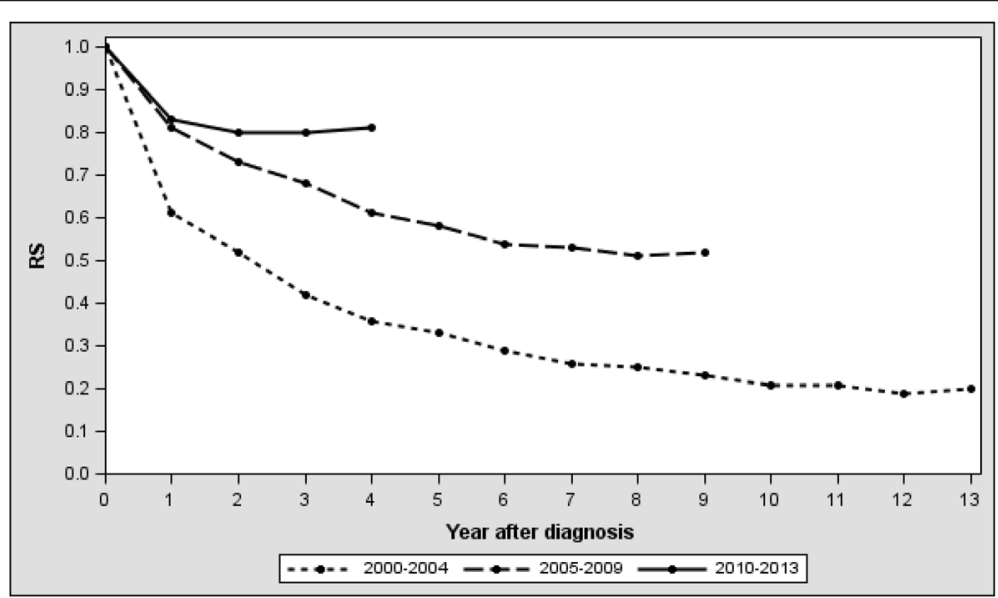

Fig. 1 Relative survival rate by period of diagnosis 


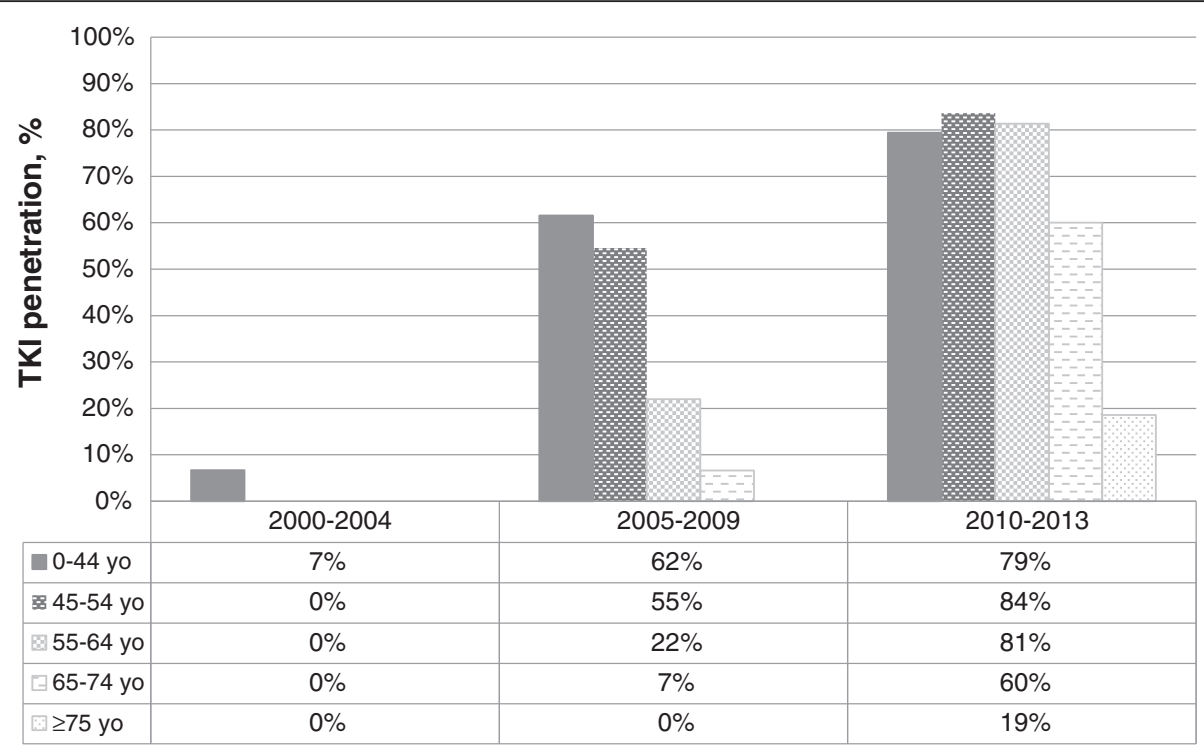

Fig. 2 Tyrosine kinase inhibitor penetrance for treatment of CML in Lithuania

hospitals. Prior to TKI entry, CML patients in Lithuania were treated with hydroxyurea and IFN $\alpha$, while only occasional eligible patient received a haematological stem cell transplant (HSCT). 5-year RSR increased from $33 \%$ in 2000-2004 to $55 \%$ in 2005-2009, when TKIs became partially available in Lithuania. Recently EUROCARE- 5 project reported haematological cancer RSRs for different European regions [34]. Here Lithuania along with Estonia, Slovakia, Poland and Bulgaria constituted the Eastern Europe region. Throughout 2000-2004 and 2005-2009 periods, 5-year CML RSR in Lithuania remained above the Eastern European registry averages, at overall European average, but below the RSR averages seen in Sweden (Table 4). Every age group 5-year RSR averages also remained lower than those reported from UK, USA and Girona province of Spain [13, 35, 36].

Table 4 5-year RSR for CML patients from registry data stratified by region of origin and time period

\begin{tabular}{lll}
\hline Source & Time period & 5 Year RSR \% (95 \% Cl) \\
\hline Europe & $2000-2002$ & $33.8(32.2-35.4)$ \\
$\quad$ Sant et al. 2014 [34] & $2003-2005$ & $45.7(43.9-47.5)$ \\
& $2006-2008$ & $54.4(52.5-56.2)$ \\
Eastern Europe $^{\mathrm{a}}$ & $2000-2002$ & $26.4(22.4-30.6)$ \\
$\quad$ Sant et al. 2014 [34] & $2003-2005$ & $28.6(25.0-32.4)$ \\
& $2006-2008$ & $35.3(30.9-39.7)$ \\
Sweden & $2001-2008$ & $80(75-83)$ \\
$\quad$ Bjorkholm et al. 2011 [2] & & \\
Lithuania & $2000-2004$ & $33(27-40)$ \\
$\quad$ Our data & $2005-2009$ & $55(47-60)$ \\
\hline
\end{tabular}

Eastern Europe region: Lithuania, Estonia, Poland, Slovakia and Bulgaria
Unfortunately, UK data in Pulte et al. study may be compounded by CML registration inaccuracies [37]. Smith et al. report demonstrates that the actual 5-year RSR in UK is probably significantly higher $(0.89$ for 2004-2011 period) and no worse than CML RSR seen in Sweden [36]. Similarly to other studies, the biggest 5 -year RSR improvements in Lithuania were evident in patient groups $<75[2,3]$. 1-year (RSR $0.46,95 \%$ CI $0.37-0.55$ ) and 5-year (RSR 0.14, $95 \%$ CI $0.07-0.23$ ) RSR in patients $\geq 75$ remained low throughout the entire 2000-2013 period.

Five-year RSR for patients newly diagnosed with CML in 2010-2013 is not available yet, but cumulative 4 -year RS for this period was $>0.80$. Relative survival for this latest Lithuanian patient cohort is approaching the 5-year RSR recorded in French cancer registries (RSR 0.83 in 2000-2009) and Swedish national registry (RSR 0.80 in 2001-2008) in the early years of TKI utilization [2, 3]. Interestingly, the patient population diagnosed with CML during the 2010-2013 period, started showing an upward RSR trend two years after the diagnosis. This finding is in line with results published by Gambacorti-Passerini et al. who show that people treated with imatinib and in cytogenic remission for $>2$ years, carry only $4.8 \%$ annual overall mortality, which is similar to matched general population [38]. It is possible that imatinib has a long term cardiovascular protective effect [39], though opposite claims have also been published [40].

The emergence of effective treatment has also sparkled enthusiasm in standardizing the CML referral pathways, formulating explicit treatment guidelines and employing the newest molecular disease monitoring 
and prognostication techniques, which have potentially led to the improvement of CML patient care and survival. Yet TKI penetrance is probably the sole most important determinant of CML survival on a country level. In Lithuania the penetrance of TKI treatment was largely determined by national reimbursement policy. Owing to healthcare resource restrictions, here patented cancer therapies have longer availability latency than in Western Europe. While in multiple Western economies imatinib entered national CML treatment guidelines as a first line CML treatment in 2001-2, imatinib became partially available in Lithuania only in 2005. During the 2005-2009 period TKI treatment was reserved only for the youngest patients: $58 \%$ patients aged $<55$ and only $8 \%$ patients $\geq 55$ received TKIs. Only from 2011 all newly diagnosed CML patients were funded to have imatinib as a first line treatment, but even during the 2010-2013 period of CML diagnosis, in Lithuania only $69 \%$ of patients were treated with TKIs.

A noteworthy study was recently published from another less affluent country - Bosnia and Herzegovina demonstrating that many patients experience a delay in receiving the TKI treatment and therefore have worse cytogenetic and molecular remission rates [41]. Individual case TKI reimbursement system seen Bosnia functioned in Lithuania between 2005 and 2011 and here the argument that delay in administering TKIs could lead to inferior outcomes is also valid.

Although excellent CML survival rates have been reported from regional population databases in France and UK, so far no other country has reported better entire country population CML survival results than Sweden $[3,12,36]$. Hoglund et al. data contradicts the criticism that clinical trial treatment efficacy results cannot be expected in general population [11]. With nearly complete CML population coverage with TKIs, survival for chronic phase CML patients aged $\leq 60$ in Sweden was close to survival of general population [12]. Since 2004 > $55 \%$ CML patients have been receiving TKIs as a first-line treatment in Sweden [12]. A French report showed that $93 \%$ of patients diagnosed with CML during 2000-2009 period were treated with TKIs [3]. Interestingly, in some countries TKI availability is not a correlate of the economic output. Due to loose regulations and easily available cheap imatinib generics, some Pacific-Asian countries have even higher TKI coverage than some Western countries that pay the full patented drug price [42].

Even during 2010-2013 period the accessibility of TKIs for patients $\geq 75$ was much smaller (18\%) than for younger population ( $81 \%$ of $<65$ years). Likewise, in USA significantly fewer elderly patients, when compared to younger patients, were given TKIs during the 20032005 observation period, though these rates would have certainly increased by now [43]. Meanwhile, Swedish national registry report shows that during 2001-2008 period $>80 \%$ of CML patients aged $\geq 75$ received TKIs [12]. Overall CML survival, when treated with TKIs, was shown to be more dependent on the number of comorbidities than on patient's age [44]. Our data demonstrates that patients $\geq 75$ presenting with CML have markedly worse ECOG performance status than younger patients and this may underlie physicians' decision to withhold the TKI treatment. However, only $60 \%$ of $65-74$ year old CML patients, who had much better performance status, were prescribed imatinib. There may well be a bias among doctors to withhold the expensive treatment from elderly patients with a view of reserving it for the younger. However, studies show that elderly CML patients benefit from TKI treatment nearly as much as younger patients and age has no objective role as a selection criteria for the TKI treatment [45].

\section{Conclusion}

In Lithuania crude CML incidence matched the European averages once strict genetic diagnostics criteria were implemented. Relative CML survival improved from 2000-2004 to 2010-2013 period and was paralleled by the increasing availability of TKI treatment. CML patients in Lithuania had better relative survival than the Eastern European average, but lower than CML patients in more affluent countries, where TKI penetrance was higher. Patients above 75 years rarely received TKIs and their relative survival remained low throughout the observation period.

\section{Additional file}

Additional file 1: Supplemetary material providing detailed data on age group-specific CR and ASR (W) of CML incidence and mortality, timeperiod specific Kaplan-Meier survival curves and ECOG performance status of different patient groups. (PDF $766 \mathrm{~kb}$ )

\section{Abbreviations}

ASR(W): age-standardized rate (weighted); CML: chronic myelogenous leukaemia; CR: crude rate; HESS: Haematological disease monitoring system; HSCT: Haematological stem cell transplant; RSR: relative survival rate; TKI: tyrosine kinase inhibitor.

\section{Competing interests}

The authors declare that they have no competing interests.

\section{Authors' contributions}

TB shaped the design of the study, analyzed the data and drafted the manuscript; IT contributed to shaping the study design and data collection; TZ - collected the data, performed statistical analysis and contributed to drafting the manuscript; $R G$ - collected the data and revised the manuscript; MJ - collected the data and revised the manuscript; LG - contributed in designing the study, collecting and analyzing the data and writing the manuscript. All authors have read and approved the manuscript.

\section{Authors' information}

Authors did not receive any specific funding to conduct the study.

\section{Acknowledgements}

We would like to acknowledge Dr. Jurate Daubariene from Panevezys Hospital, Dr. Danguole Ramanauskiene from Siauliai Hospital, Dr. Giedre 
Smailyte from National Cancer Institute and Dr. Ugnius Mickys from National Pathology Cente for their help in collecting data. None of them received any funding.

\section{Author details}

${ }^{1}$ Clinical Medical School, University of Oxford, Oxford, UK. ${ }^{2}$ Centre for Evidence-Based Medicine, Clinics of Internal, Family Medicine and Oncology, Faculty of Medicine, Vilnius University, M. K. Ciurlionio str. 21, 03101 Vilnius, Lithuania. ${ }^{3}$ Hematology, Oncology and Transfusion Medicine Center, Vilnius University Hospital Santariskiu Klinikos, Santariskiu 2, 08661 Vilnius, Lithuania. ${ }^{4}$ Clinics of Oncology and Hematology, Hospital of Lithuanian University of Health Sciences Kauno Klinikos, Eiveniu g. 2, 50009 Kaunas, Lithuania. ${ }^{5}$ Department of Oncology Haematology, Klaipeda Seamen Hospital, Liepojos 45, 92288 Klaipeda, Lithuania. ${ }^{6}$ Clinics of Internal, Family Medicine and Oncology, Faculty of Medicine, Vilnius University, M. K. Ciurlionio str. 21, 03101 Vilnius, Lithuania.

Received: 16 November 2015 Accepted: 1 March 2016

Published online: 08 March 2016

\section{References}

1. Cohen MH, Williams G, Johnson JR, Duan J, Gobburu J, Rahman A, et al. Approval summary for imatinib mesylate capsules in the treatment of chronic myelogenous leukemia. Clin Cancer Res. 2002;8(5):935-42.

2. Bjorkholm M, Ohm L, Eloranta S, Derolf A, Hultcrantz M, Sjoberg J, et al. Success story of targeted therapy in chronic myeloid leukemia: a population-based study of patients diagnosed in Sweden from 1973 to 2008. J Clin Oncol. 2011;29(18):2514-20.

3. Penot A, Preux PM, Le Guyader S, Collignon A, Herry A, Dufour V, et al. Incidence of chronic myeloid leukemia and patient survival: results of five French population-based cancer registries 1980-2009. Leuk Lymphoma. 2015;56(6):1771-7.

4. Kantarjian H, Talpaz M, O'Brien S, Garcia-Manero G, Verstovsek S, Giles F, et al. High-dose imatinib mesylate therapy in newly diagnosed Philadelphia chromosome-positive chronic phase chronic myeloid leukemia. Blood. 2004;103(8):2873-8.

5. Kantariian HM, Cortes JE, O'Brien S, Giles F, Garcia-Manero G, Faderl S, et al. Imatinib mesylate therapy in newly diagnosed patients with Philadelphia chromosome-positive chronic myelogenous leukemia: high incidence of early complete and major cytogenetic responses. Blood. 2003;101(1):97-100.

6. Kantarjian H, Sawyers C, Hochhaus A, Guilhot F, Schiffer C, GambacortiPasserini $C$, et al. Hematologic and cytogenetic responses to imatinib mesylate in chronic myelogenous leukemia. N Engl J Med. 2002;346(9):645-52.

7. Mahon FX, Rea D, Guilhot J, Guilhot F, Huguet F, Nicolini F, et al. Discontinuation of imatinib in patients with chronic myeloid leukaemia who have maintained complete molecular remission for at least 2 years: the prospective, multicentre Stop Imatinib (STIM) trial. Lancet Oncol. 2010;11(11):1029-35

8. Abboud C, Berman E, Cohen A, Cortes J, DeAngelo D, Deininger M, et al. The price of drugs for chronic myeloid leukemia $(\mathrm{CML})$ is a reflection of the unsustainable prices of cancer drugs: from the perspective of a large group of CML experts. Blood. 2013;121(22):4439-42

9. Conti RM, Padula WW, Larson RA. Changing the cost of care for chronic myeloid leukemia: the availability of generic imatinib in the USA and the EU. Ann Hematol. 2015;94 Suppl 2:S249-257.

10. Romero M, Chavez D, De Los RM, Alvis-Guzman N. Cost-effectiveness of nilotinib, dasatinib and imatinib as first-line treatment for chronic myeloid leukemia in Colombia, 2012. Biomedica. 2014;34(1):48-59.

11. Pulte D, Gondos A, Redaniel MT, Brenner H. Survival of patients with chronic myelocytic leukemia: comparisons of estimates from clinical trial settings and population-based cancer registries. Oncologist. 2011;16(5):663-71.

12. Hoglund M, Sandin F, Hellstrom K, Bjoreman M, Bjorkholm M, Brune M, et al. Tyrosine kinase inhibitor usage, treatment outcome, and prognostic scores in CML: report from the population-based Swedish CML registry. Blood. 2013;122(7):1284-92

13. Pulte D, Redaniel MT, Bird J, Jeffreys M. Survival for patients with chronic leukemias in the US and Britain: Age-related disparities and changes in the early 21st century. Eur J Haematol. 2015;94(6):540-5.

14. Faber E, Muzik J, Koza V, Demeckova E, Voglova J, Demitrovicova L, et al. Treatment of consecutive patients with chronic myeloid leukaemia in the cooperating centres from the Czech Republic and the whole of Slovakia after 2000-a report from the population-based CAMELIA Registry. Eur J Haematol. 2011;87(2):157-68.

15. Chihara D, Ito H, Matsuda T, Katanoda K, Shibata A, Saika K, et al. Decreasing trend in mortality of chronic myelogenous leukemia patients after introduction of imatinib in Japan and the U.S. Oncologist. 2012;17(12):1547-50.

16. Dawson B, Trapp RG. Basic \& clinical biostatistics. Monterey: McGraw-Hill; 2001.

17. Boniol M, Heanue M. Age-standardisation and denominators. In: Curado MP, Edwards B, Shin HR, Storm H, Ferlay J, Heanue M, Boyle P, editors. Cancer incidence in five continents. 2008. p. 1-837.

18. United Nations. World Population Prospects, the 2015 Revision [http://esa. un.org/wpp/Excel-Data/population.htm]

19. Dickman PW, Sloggett A, Hills M, Hakulinen T. Regression models for relative survival. Stat Med. 2004;23(1):51-64.

20. Kaplan EL, Meier P. Nonparametric Estimation from Incomplete Observations. J Am Stat Assoc. 1958;53(282):457-81.

21. Ederer $\mathrm{F}$, Heise $\mathrm{H}$. Instructions to IBM 650 programmers in processing survival computations. In: Methodological note. 1959.

22. Hoffmann VS, Baccarani M, Hasford J, Lindoerfer D, Burgstaller S, Sertic D, et al. The EUTOS population-based registry: incidence and clinical characteristics of 2904 CML patients in 20 European Countries. Leukemia. 2015;29(6):1336-43.

23. Maynadie M, De Angelis R, Marcos-Gragera R, Visser O, Allemani C, Tereanu $C$, et al. Survival of European patients diagnosed with myeloid malignancies: a HAEMACARE study. Haematologica. 2013;98(2):230-8.

24. Sant M, Allemani C, Tereanu C, De Angelis R, Capocaccia R, Visser O, et al. Incidence of hematologic malignancies in Europe by morphologic subtype: results of the HAEMACARE project. Blood. 2010;116(19):3724-34.

25. Smith A, Howell D, Patmore R, Jack A, Roman E. Incidence of haematological malignancy by sub-type: a report from the Haematological Malignancy Research Network. Br J Cancer. 2011;105(11):1684-92.

26. Chen $Y$, Wang $H$, Kantarjian $H$, Cortes J. Trends in chronic myeloid leukemia incidence and survival in the United States from 1975 to 2009. Leuk Lymphoma. 2013;54(7):1411-7.

27. Chronic Myeloid Leukemia [http://seer.cancer.gov/statfacts/html/cmyl.html]

28. Giri S, Pathak R, Martin MG, Bhatt VR. Characteristics and survival of BCR/ABL negative chronic myeloid leukemia: a retrospective analysis of the Surveillance, Epidemiology and End Results database. Therapeutic advances in hematology. 2015:6(6):308-12.

29. Breccia M, Biondo F, Latagliata R, Carmosino I, Mandelli F, Alimena G. Identification of risk factors in atypical chronic myeloid leukemia. Haematologica. 2006;91(11):1566-8.

30. Druker BJ, Guilhot F, O'Brien SG, Gathmann I, Kantarjian H, Gattermann N, et al. Five-year follow-up of patients receiving imatinib for chronic myeloid leukemia. N Engl J Med. 2006;355(23):2408-17.

31. Kantarjian H, O'Brien S, Jabbour E, Garcia-Manero G, Quintas-Cardama A, Shan J, et al. Improved survival in chronic myeloid leukemia since the introduction of imatinib therapy: a single-institution historical experience. Blood. 2012;119(9):1981-7.

32. Pfirrmann M, Saussele S, Baccarani M, Guilhot J, Cervantes F, Ossenkoppele GJ, Lindoerfer D, Hoffmann VS, Castagnetti F, Hehlmann R et al. Survival and Prognosis in Patients with First-Line Imatinib Treatment Under Particular Consideration of Death Due to Chronic Myeloid Leukemia. Blood. 2014;124(21):153.

33. Lauseker M, Hasford J, Pfirrmann M, Hehlmann R. The impact of health care settings on survival time of patients with chronic myeloid leukemia. Blood. 2014;123(16):2494-6.

34. Sant M, Minicozzi $P$, Mounier M, Anderson LA, Brenner $H$, Holleczek $B$, et al. Survival for haematological malignancies in Europe between 1997 and 2008 by region and age: results of EUROCARE-5, a population-based study. Lancet Oncol. 2014;15(9):931-42.

35. Osca-Gelis G, Puig-Vives M, Saez M, Gallardo D, Lloveras N, Guardia R, et al. Is survival in myeloid malignancies really improving? A retrospective 15-year population-based study. Leuk Lymphoma. 2015;56(4):896-902.

36. Smith AG, Painter D, Howell DA, Evans P, Smith G, Patmore R, et al. Determinants of survival in patients with chronic myeloid leukaemia treated in the new era of oral therapy: findings from a UK population-based patient cohort. BMJ open. 2014;4(1):e004266.

37. Trends in incidence and outcome for haematological cancers in England: 2001-2010. In: National cancer intelligence network. 2014.

38. Gambacorti-Passerini $C$, Antolini $L$, Mahon FX, Guilhot F, Deininger M, Fava $\mathrm{C}$, et al. Multicenter independent assessment of outcomes in chronic 
myeloid leukemia patients treated with imatinib. J Natl Cancer Inst. 2011;103(7):553-61.

39. Schellings MW, Baumann M, van Leeuwen RE, Duisters RF, Janssen SH, Schroen B, et al. Imatinib attenuates end-organ damage in hypertensive homozygous TGR(mRen2)27 rats. Hypertension. 2006;47(3):467-74.

40. Kerkela R, Grazette L, Yacobi R, lliescu C, Patten R, Beahm C, et al. Cardiotoxicity of the cancer therapeutic agent imatinib mesylate. Nat Med. 2006;12(8):908-16.

41. Kurtovic-Kozaric A, Hasic A, Radich JP, Bijedic V, Nefic H, Eminovic I, Kurtovic S, Colakovic F, Kozaric M, Vranic S et al. The reality of cancer treatment in a developing country: the effects of delayed TKI treatment on survival, cytogenetic and molecular responses in chronic myeloid leukaemia patients. British journal of haematology. 2015;172(3):420-7.

42. Kim DW, Banavali SD, Bunworasate U, Goh YT, Ganly P, Huang H, et al. Chronic myeloid leukemia in the Asia-Pacific region: current practice, challenges and opportunities in the targeted therapy era. Leuk Res. 2010;34(11):1459-71

43. Wiggins CL, Harlan LC, Nelson HE, Stevens JL, Willman CL, Libby EN, et al. Age disparity in the dissemination of imatinib for treating chronic myeloid leukemia. Am J Med. 2010;123(8):764. e761-769.

44. Saussele S, Krauss MP, Hehlmann R, Lauseker M, Proetel U, Kalmanti L, et al. Impact of comorbidities on overall survival in patients with chronic myeloid leukemia: results of the randomized CML Study IV. Blood. 2015;126(1):42-9.

45. Gugliotta G, Castagnetti F, Palandri F, Breccia M, Intermesoli T, Capucci A, et al. Frontline imatinib treatment of chronic myeloid leukemia: no impact of age on outcome, a survey by the GIMEMA CML Working Party. Blood. 2011;117(21):5591-9.

\section{Submit your next manuscript to BioMed Central and we will help you at every step:}

- We accept pre-submission inquiries

- Our selector tool helps you to find the most relevant journal

- We provide round the clock customer support

- Convenient online submission

- Thorough peer review

- Inclusion in PubMed and all major indexing services

- Maximum visibility for your research

Submit your manuscript at www.biomedcentral.com/submit

C Biomed Central 